\title{
Geoinformation postgraduate education at Universiti Teknologi Malaysia - towards a centre of high quality postgraduate education and research
}

\author{
S. Peters ${ }^{\text {a }}$, K. D. Kanniah ${ }^{\text {a }}$, A. A. Rahman ${ }^{\text {a }}$
}

${ }^{a}$ Faculty of Geoinformation and Real Estate, Dept. of Geoinformation, Universiti Teknologi Malaysia

KEY WORDS: Postgraduate education, Geoinformation, UTM, Malaysia

\section{ABSTRACT:}

Studying at Universiti Teknologi Malaysia (UTM) will ensure academic and technological excellence. The Faculty of Geoinformation and Real Estate (FGHT), established in 1972, focus on education and research for undergraduate as well as postgraduate programs in the related disciplines such as geomatic engineering, geoinformatics, remote sensing, property management and land administration $\&$ development. FGHT strives to be a leading academic center in geoinformation and real estate in Southeast Asia. Graduates and alumni form major strong professional societies and work force in the related industries. Many of our graduates end up with good jobs not just in Malaysia but also in other countries (Asian, Middle East, Africa and Europe). The strong team and knowledgeable academic members in this faculty provide excellent ingredients for the success of the programs (i.e. with the relevant and up-to-date curriculum and syllabus). FGHT is continuously working to provide and offer first-class geoinformation and real estate education and research in the country and be at a par with other leading institutions in other parts of the globe. The Department of Geoinformation at FGHT runs a Bachelor of Engineering in Geomatic and a Bachelor of Science in Geoinformatics. At the postgraduate levels, namely M.Sc. and $\mathrm{PhD}$ programs, the offered disciplines are Geomatic Engineering, Geoinformatics and Remote Sensing. In the following, the state of the art of FGHT's postgraduate education in Geoinformation is presented, including a comparison with other universities in Malaysia, program content and curriculum information, alumni statistics as well as future strategies.

Table 1. Geomatic, Geoinformatics and Remote Sensing (RS) university programs in Malaysia

\begin{tabular}{|c|c|c|c|c|c|c|}
\hline & University & Course name & Degree & $\begin{array}{c}\text { Duration } \\
\text { (years) }\end{array}$ & $\begin{array}{l}\text { Tuition } \\
\text { (RM) }\end{array}$ & $\begin{array}{l}\text { Tuition for } \\
\text { foreigners }\end{array}$ \\
\hline \multirow{4}{*}{ 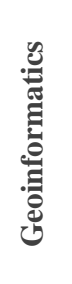 } & UTM & Geoinformatics & B.Sc. & 4 & 6880 & 11830 \\
\hline & UTM & Geoinformatics & M.Sc. & 1.5 & 18980 & 18980 \\
\hline & Universiti Teknologi MARA & $\begin{array}{l}\text { Geographical Information } \\
\text { Science }\end{array}$ & M.Sc. & 1 & 1188 & 3930 \\
\hline & Universiti Malaysia Sarawak & $\begin{array}{l}\text { Spatial Analysis and } \\
\text { Modeling for GIS }\end{array}$ & M.Sc. & 2 & 6600 & 9400 \\
\hline \multirow{5}{*}{ 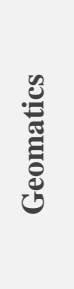 } & UTM & Geomatic & B.Eng. & 4 & 6880 & 11830 \\
\hline & UTM & Geomatic & M.Sc. & 1.5 & 18980 & 18980 \\
\hline & Geomatika University College & Geomatic Engineering & Diploma & 3 & 24000 & 24000 \\
\hline & Universiti Teknologi MARA & $\begin{array}{l}\text { Surveying Science and } \\
\text { Geomatics }\end{array}$ & $\begin{array}{l}\text { B.Sc. } \\
\text { (Hons) }\end{array}$ & 2.5 & 600 & 1200 \\
\hline & Infrastructure University Kuala Lumpur & Geomatic Engineering & Diploma & 2.5 & 24000 & 31300 \\
\hline \multirow{2}{*}{ ॠે } & UTM & Remote Sensing & M.Sc. & 1.5 & 18980 & 18980 \\
\hline & Universiti Putra Malaysia & Remote Sensing and GIS & M.Sc. & 2 & 4200 & 8400 \\
\hline
\end{tabular}

Table 1 provides an overview of Geoinformation related university programs in Malaysia including awarded degree, program duration, and current tuition fees (July/2015). The table clearly demonstrates that UTM offers the most comprehensive undergraduate and postgraduate education in the field of Geoinformation. In particular the B.Sc. and M.Sc. in Geoinformatics are unique programs not only in Malaysia but also in entire South East Asia.

\section{M.Sc. in Geoinformatics/ Geomatic/ Remote Sensing at FGHT}

The M.Sc. in Geoinformatics, the M.Sc. in Geomatic and the M,Sc. in Remote Sensing are international programs, fully conducted in English language. The Master's program is divided in two modes which are course work and research. As illustrated in Table 2-4, each program by course work consists of 6 to 7 Core courses, 2-3 elective courses and 1 University course. Besides these taught subjects, students are required to submit a Master Project worth of 8 credits. To graduate, students must complete a total 45 credits. Students are assessed through assignments, presentations and final examination. The programs are carried out in full time or part time basis. The full time basis will take 3 semesters by thought course and 4 semesters by research respectively. Part time basis will take about 8 semesters to graduate. 
Table 2. Curriculum of M.Sc. in Geoinformatics (by course work) at UTM FGHT.

\begin{tabular}{|l|l|c|}
\hline Course type & Course name & Credits \\
\hline \multirow{5}{*}{ UNIVERSITY COURSE } & Science and Social Development & 3 \\
\hline \multirow{5}{*}{ CORE COURSES } & Principles of GIS & 4 \\
\hline & Geospatial Databases & 4 \\
\hline & Spatial Analysis \& Modeling & 4 \\
\hline & Research Methods in GIS & 3 \\
\hline & Geospatial Data Management & 4 \\
\hline & Programming for GIS & 3 \\
\hline \multirow{5}{*}{$\begin{array}{l}\text { ELECTIVE COURSES } \\
\text { (3 courses to be choosen })\end{array}$} & Geospatial Data Acquisition and Processing & 4 \\
\hline & GIS Project Management & 4 \\
\hline & GIS Applications & 4 \\
\hline & GIS Application Development & 4 \\
\hline & GIS Implementation & 4 \\
\hline & GIS \& Public Policy & 4 \\
\hline & Cartography and Visualisation & 4 \\
\hline THESIS & Master's Project & 8 \\
\hline
\end{tabular}

Table 3. Curriculum of M.Sc. in Geomatic (by course work) at UTM FGHT.

\begin{tabular}{|c|c|c|}
\hline Course type & Course name & Credits \\
\hline UNIVERSITY COURSE & Science and Social Development & 3 \\
\hline \multirow{6}{*}{ CORE COURSES } & Geomatics Positioning/GNSS & 4 \\
\hline & Geomatics Data Analysis & 4 \\
\hline & Advanced Mapping & 4 \\
\hline & Geomatics Project Management & 3 \\
\hline & Geographical Information System & 4 \\
\hline & Research Methodology & 3 \\
\hline \multicolumn{3}{|c|}{ ELECTIVE COURSES (choose 1 specialization) } \\
\hline \multirow{3}{*}{$\begin{array}{l}\text { SPECIALIZATION A: } \\
\text { SURVEY \& MAPPING }\end{array}$} & Cadastral Studies & 4 \\
\hline & Advanced Engineering Survey & 4 \\
\hline & Hydrographic Survey Application & 4 \\
\hline \multirow{3}{*}{$\begin{array}{l}\text { SPECIALIZATION B: } \\
\text { UTILITY MAPPING }\end{array}$} & Underground Utility Surveying & 4 \\
\hline & Geophysics for Utility Surveying & 4 \\
\hline & Utility Mapping Standard \& Practice & 4 \\
\hline THESIS & Master's Project & 8 \\
\hline
\end{tabular}

Table 4. Curriculum of M.Sc. in Remote Sensing. (by course work) at UTM FGHT

\begin{tabular}{|l|l|c|}
\hline Course type & Course name & Credits \\
\hline UNIVERSITY COURSE & Science and Social Development & 3 \\
\hline \multirow{5}{*}{ CORE COURSES } & Remote Sensing Technology & 4 \\
\hline & Digital Image Processing & 4 \\
\hline & Microwave Remote Sensing & 4 \\
\hline & Research Methods in RS & 3 \\
\hline & Geographical Information System and Spatial Analysis & 4 \\
\hline & GPS Surveying & 3 \\
\hline \multirow{2}{*}{$\begin{array}{l}\text { ELECTIVE COURSES } \\
\text { (2 courses to be choosen })\end{array}$} & Applications of Remote Sensing & 4 \\
\hline & Atmospheric Physics & 4 \\
\hline & Advance Digital Image Processing & 4 \\
\hline & Satellite System and Earth Station & 4 \\
\hline THESIS & Remote Sensing Project Management & 4 \\
\hline & Master's Project & 8 \\
\hline
\end{tabular}

FGHT-Department of Geoinformation offers Doctor of Philosophy $(\mathrm{PhD})$ program in three fields of specializations Geoinformatics, Geomatics and Remote Sensing. The programmes can be carried out in full time and part time basis. The full time basis will take 6 semesters and the part time basis will take about 12 semesters to graduate. Students are required to take course on Research Methodology and 3 credits University Course. 


\section{Student's statistics}

Figure 1 shows the number of FGHT Geoinformation postgraduate students in various disciplines and their country of origin at FGHT for the past 5 years. FGHT-Department of Geoinformation admitted about 250 students during the last 5 years. Students come from altogether 14 different countries, mainly from South East Asia, Middle East, and Africa.

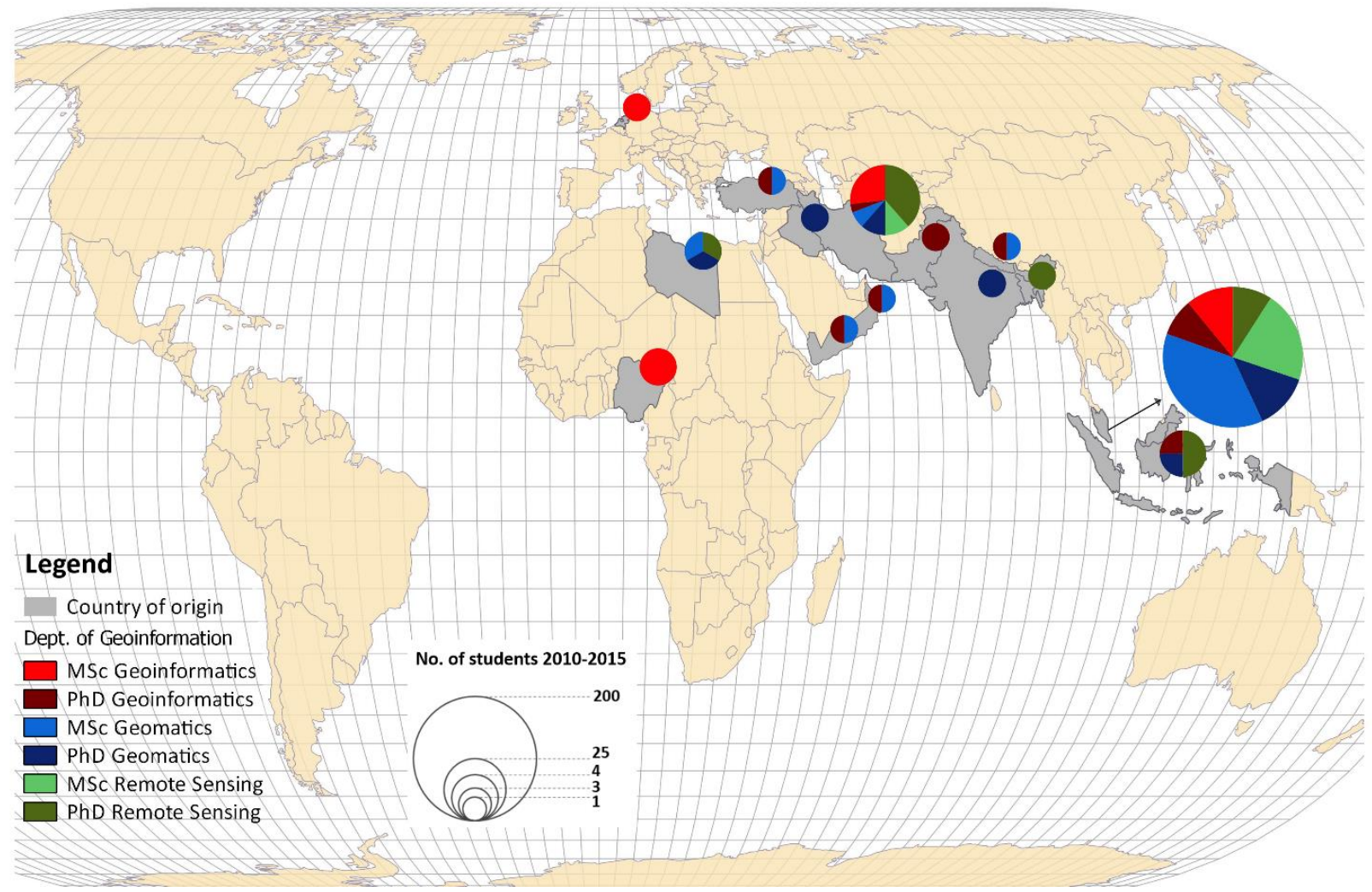

Figure 1. FGHT-Postgraduate statistics 2010-2015 (number of students according to their country of origin and programmes

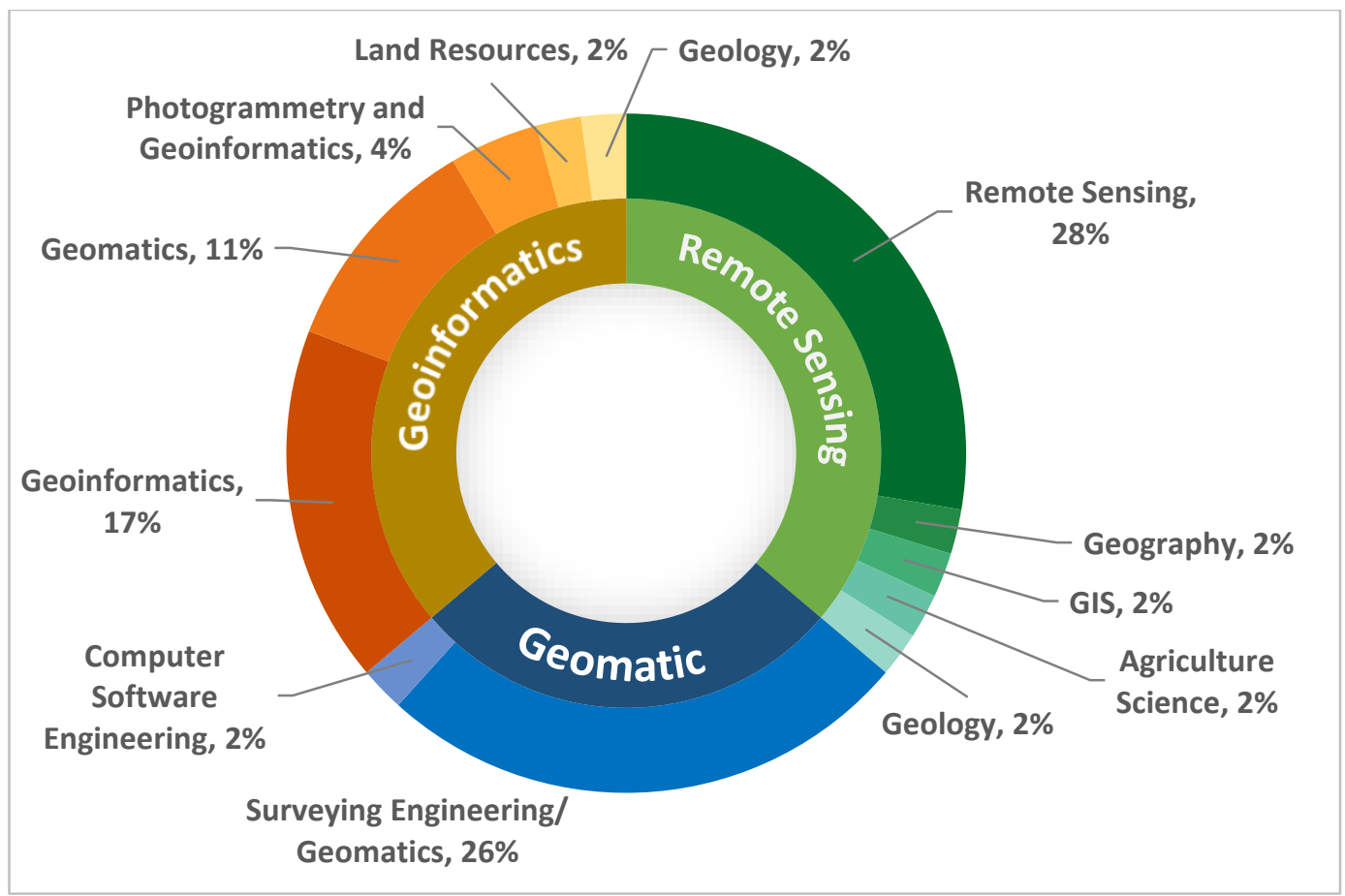

Figure 2. Entry qualification degree (FGHT-PG students 2010-2015) 
Figure 2 provides a closer insight about the study background of Postgraduate students at the Department of Geoinformation (UTM). The inner circle represents FGHT M.Sc. and PhD programs in Geoinformatics, Geomatic and Remote Sensing. The outer circle illustrates study background of enrolled students. About $\mathbf{3 0 \%}$ of these enrolled/registered postgraduate students obtained their first degree (B.Sc.) in Geoinformatics/ Geomatic or Remote Sensing) at UTM.

Furthermore, Figure 3 shows carrier activities of our alumni after graduation. One of the major goals is to train future researchers in the field of geoinformation. Alumni statistics shows that the majority of our graduates find a job in academic field respectively continued their studies with doing a PhD.

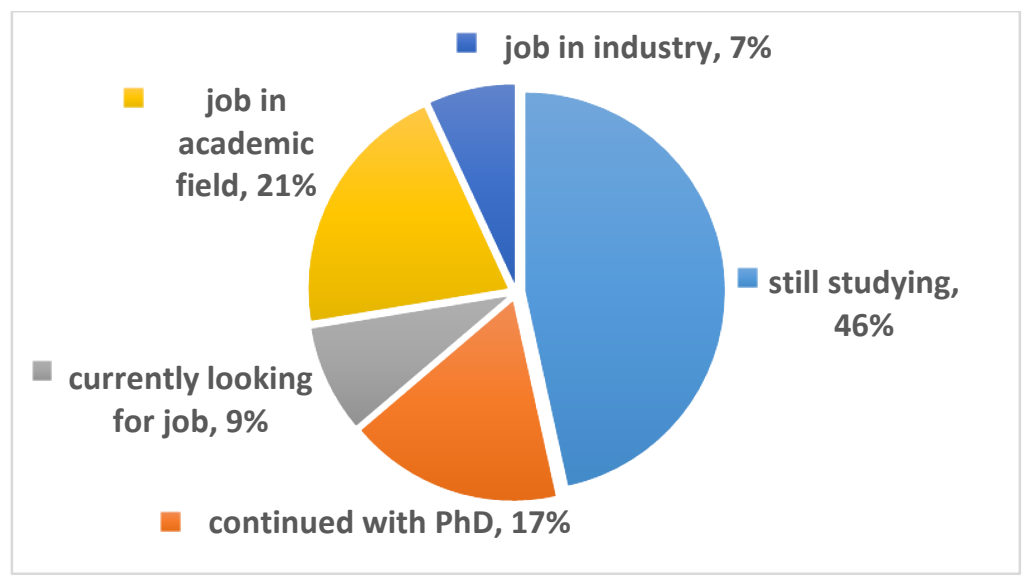

Figure 3. Alumni career activities (FGHT-PG students 2010-2015)

\section{Discussion and future strategies}

One of the major objectives of Department of Geoinformation at UTM is to maintain the state of the art in geoinformation education and research in Malaysia and to spearhead FGHT towards a centre of high quality postgraduate education and research. Therefore, different strategies are considered. First, we aim to increase the number of postgraduate students. We currently plan to perform an extensive national and international program marketing, including online marketing, publications in academic journals and magazines, presentations on international conferences, performing special events such as international summer school, etc. Furthermore, our consecutive master's programs are built upon our respective bachelor's programs. However, as shown in Figure 2, in particular for our M.Sc. in Geoinformatics, more than half of the admitted students obtained their entry qualification in related but different fields. Thus, one challenge is to harmonize students' knowledge. Therefore, we briefly repeat important fundamentals in the first semester of the Master course.

Besides, FGHT is regularly reviewing and improving program curricula through students' evaluations and external reviewers. Moreover, FGHT strives towards a high ranking and bench marking with renowned international ranking bodies such as THE (The Higher Education). 